\title{
Listeria marthii sp. nov., isolated from the natural environment, Finger Lakes National Forest
}

Correspondence
Lewis M. Graves
LGraves@cdc.gov

\section{INTRODUCTION}

The genus Listeria contains six species of low $\mathrm{G}+\mathrm{C}$ content Gram-positive bacteria closely related to the genus Bacillus (Collins et al., 1991; Sallen et al., 1996). The species are Listeria monocytogenes, L. ivanovii, L. innocua, L. seeligeri, $L$. welshimeri and L. grayi (Rocourt \& Buchrieser, 2007). L.
Lewis M. Graves, ${ }^{1}$ Leta O. Helsel, ${ }^{1}$ Arnold G. Steigerwalt, ${ }^{1}$ Roger E. Morey, ${ }_{1}^{1}$ Maryam I. Daneshvar, ${ }^{1}$ Sherry E. Roof, ${ }^{2}$ Renato H. Orsi, ${ }^{2}$ Esther D. Fortes, ${ }^{2}$ Sara R. Milillo, ${ }^{2}$ Henk C. den Bakker, ${ }^{2}$ Martin Wiedmann, ${ }^{2}$ Balasubramanian Swaminathan ${ }^{1}$ and Brian D. Sauders ${ }^{3}$

\footnotetext{
${ }^{1}$ Enteric Diseases Laboratory Branch and Bacterial Zoonoses Branch, Division of Foodborne, Bacterial, and Mycotic Diseases, National Center for Zoonotic, Vector-borne and Enteric Diseases, Coordinating Center for Infectious Disease, Centers for Disease Control and Prevention, Atlanta, GA 30333, USA

${ }^{2}$ Department of Food Science, Cornell University, Ithaca, NY 14853, USA

${ }^{3}$ New York State Department of Agriculture and Markets Food Laboratory Division, Albany, NY 12235, USA
}

Four isolates (FSL S4-120', FSL S4-696, FSL S4-710, and FSL S4-965) of Gram-positive, motile, facultatively anaerobic, non-spore-forming bacilli that were phenotypically similar to species of the genus Listeria were isolated from soil, standing water and flowing water samples obtained from the natural environment in the Finger Lakes National Forest, New York, USA. The four isolates were closely related to one another and were determined to be the same species by whole genome DNA-DNA hybridization studies ( $>82 \%$ relatedness at $55{ }^{\circ} \mathrm{C}$ and $>76 \%$ relatedness at $70{ }^{\circ} \mathrm{C}$ with $0.0-0.5 \%$ divergence). $16 \mathrm{~S}$ rRNA gene sequence analysis confirmed their close phylogenetic relatedness to Listeria monocytogenes and Listeria innocua and more distant relatedness to Listeria welshimeri, L. seeligeri, L. ivanovii and L. grayi. Phylogenetic analysis of partial sequences for $\operatorname{sig} B$, gap, and prs showed that these isolates form a wellsupported sistergroup to $L$. monocytogenes. The four isolates were sufficiently different from $L$. monocytogenes and $L$. innocua by DNA-DNA hybridization to warrant their designation as a new species of the genus Listeria. The four isolates yielded positive reactions in the AccuProbe test that is purported to be specific for $L$. monocytogenes, did not ferment L-rhamnose, were nonhaemolytic on blood agar media, and did not contain a homologue of the $L$. monocytogenes virulence gene island. On the basis of their phenotypic characteristics and their genotypic distinctiveness from $L$. monocytogenes and $L$. innocua, the four isolates should be classified as a new species within the genus Listeria, for which the name Listeria marthii sp. nov. is proposed. The type strain of $L$. marthii is FSL S4 $-120^{\top}$ (=ATCC BAA- $1595^{\top}=$ BEIR NR $9579^{\top}=$ CCUG $\left.56148^{\top}\right)$. L. marthii has not been associated with human or animal disease at this time.

The GenBank/EMBL/DDBJ accession number for the 16S rRNA gene sequences of FSL S4-696, FSL S4-965, FSL S4-120 ${ }^{\top}$ and FSL S4-710 are EU545980 to EU545983, respectively. The accession number for the sequence of the ldh-prs intergenic region of FSL S4-696 is FJ692340.

EcoRI ribotype and PFGE patterns, sources and geographical origin, AccuProbe test results and differentiating physiological characteristics, GenBank accession numbers of sequences used for the sigB-gap-prs phylogenetic analysis, and primer sequences used to screen for the presence/absence of $L$. monocytogenes virulence genes are available with the online version of this paper. 
virulence genes hly (which encodes a haemolysin), $\operatorname{prf} A$, $p l c A, m p l$, act $A$ and plcB. While L. monocytogenes is a human and animal pathogen, and L. ivanovii is an animal pathogen (predominantly linked to disease in sheep), $L$. seeligeri, despite the presence of the virulence gene homologues, has been rarely linked to disease in humans or animals (Gouin et al., 1994; Rocourt et al., 1983, 1986).

The phylogeny of the members of the genus Listeria suggests a common ancestor of a clade containing $L$. monocytogenes and $L$. innocua, as well as a common ancestor of a second clade containing $L$. seeligeri, $L$. ivanovii and $L$. welshimeri. Both of these clades contain species with and without the virulence gene cluster, which is found in the same genomic location in all three species with this cluster. It has been hypothesized that the evolution of the genus Listeria included an ancestor with the virulence gene cluster and two independent deletion events that led to a loss of the virulence gene cluster in members of both of these clades (Kuhn \& Goebel, 2007; Nightingale et al., 2006). The status of $L$. grayi is still uncertain, but current sequencing efforts will soon resolve this more distantly related species (Hain et al., 2007; Kuhn \& Goebel, 2007).

Although some recent reports have identified and described unusual Listeria isolates, including haemolytic Listeria isolates that contain the virulence gene cluster but are classified into the species L. innocua (Johnson et al., 2004), no new species of the genus Listeria have been described since 1985. In this report, we describe polyphasic analysis of four Listeria-like bacilli that were isolated from the natural environment in the Finger Lakes region of New York and propose that they should be placed in a new species within the genus Listeria.

\section{METHODS}

Bacterial strains. The strains studied, along with their sources, geographical origins and GenBank Accession numbers for 16S rRNA gene sequences, are presented in Supplementary Table S1 (available in IJSEM Online). Four Listeria-like isolates (FSL S4-120 ${ }^{\mathrm{T}}$, FSL S4-696, FSL S4-710 and FSL S4-965, hereafter referred to as the FSL S4isolates) were characterized in this investigation. Isolates FSL S4- $120^{\mathrm{T}}$, FSL S4-696, FSL S4-710 and FSL S4-965 were cultured from soil in a forest area $\left(42^{\circ} 26^{\prime} 36^{\prime \prime} \mathrm{N} 76^{\circ} 48^{\prime} 53^{\prime \prime} \mathrm{W}\right)$, a standing water puddle $\left(42^{\circ} 20^{\prime} 38^{\prime \prime} \mathrm{N} 76^{\circ} 39^{\prime} 41^{\prime \prime} \mathrm{W}\right)$, a flowing water runoff $\left(42^{\circ} 20^{\prime} 37^{\prime \prime} \mathrm{N}\right.$

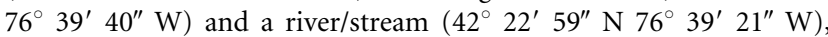
respectively, via environmental samples collected in the Finger Lakes National Forest (http://www.fs.fed.us/r9/forests/greenmountain/htm/ fingerlakes/f_home.htm) and Connecticut Hill Wildlife Management Area, which is located in the Finger Lakes region of New York, USA.

The FSL S4-isolates were cultured on heart infusion agar supplemented with $5 \%$ rabbit blood (RBA) (BBL Microbiology Systems) for use in conventional biochemical tests and incubated at $35^{\circ} \mathrm{C}$ in a candle jar. All strains were stored as suspensions in defibrinated rabbit blood in liquid nitrogen and in trypticase soy broth $+20 \%$ glycerol at $-70{ }^{\circ} \mathrm{C}$.

AccuProbe, phenotypic tests and growth range. The AccuProbe (Ninet et al., 1992; Okwumabua et al., 1992) test was performed according to the manufacturer's instructions (Gen-Probe). Liquid broth, semi-solid media and other plating media were incubated aerobically at $1,4,25,30,37,43$ or $45{ }^{\circ} \mathrm{C}$. Biochemical testing was done using previously described conventional methods (Weyant et al., 1996). All biochemical tests were performed at $35{ }^{\circ} \mathrm{C}$ in an aerobic incubator except for the temperature growth range tests, which were performed at temperatures ranging from $1{ }^{\circ} \mathrm{C}$ to $45{ }^{\circ} \mathrm{C}$. The oxidase, catalase and growth temperature tests were read after 1 day of incubation. All other biochemical tests were read after 1,2, and 7 days of incubation (Supplementary Table S2). Temperature growth range tests were done using trypticase soy broth (Becton and Dickinson Company) and sampled up to 30 days. Isolates were also characterized using the API-Listeria test strips (Bille et al., 1992).

Cellular fatty acid analysis. Cells from 2 day-old cultures were saponified, and the liberated fatty acids were methylated and analysed by capillary GLC (Weyant et al., 1996). Profiles were identified using a commercial system (MIDI).

DNA relatedness and $\mathbf{G}+\mathbf{C}$ determination. All bacteria were cultured on 20-30 RBA plates and incubated for $24 \mathrm{~h}$ at $35^{\circ} \mathrm{C}$. Cells were harvested and lysed, and the DNA was isolated and purified according to the method of Brenner et al. (1982). DNA from $L$. monocytogenes ATCC $15313^{\mathrm{T}}$ and FSL S4-120 $0^{\mathrm{T}}$ was labelled with $\left[{ }^{32} \mathrm{P}\right] \mathrm{dCTP}$ using a commercial nick translation kit (Bethesda Research Laboratories) and tested for reassociation to unlabelled DNA from the same strain (homologous reaction) as well as to other strains and to the type and reference strains studied (heterologous reactions). Relative binding ratios ([percentage heterologous DNA bound to hydroxyapatite/percentage homologous DNA bound to hydroxyapatite] $\mathrm{x}$ 100) and percentage divergence (the percentage of unpaired bases in related DNA sequences) were calculated as described previously (Brenner et al., 1982). Divergence was calculated to the nearest $0.5 \%$, with each decrease of $1{ }^{\circ} \mathrm{C}$ in thermal stability of a heterologous DNA duplex due to approximately $1.0 \%$ unpaired bases within related DNA (Bonner et al., 1973). All reactions were done in duplicate at the optimal temperature of $55{ }^{\circ} \mathrm{C}$ for labelled DNA from the type strain (FSL S4-120 $0^{\mathrm{T}}$ ) and L. monocytogenes ATCC $15313^{\mathrm{T}}$. The $\mathrm{G}+\mathrm{C}$ content $(\mathrm{mol} \%)$ was determined for strains FSL S4-120 and ATCC $15313^{\mathrm{T}}$ by thermal denaturation (Mandel et al., 1970).

165 rRNA gene sequencing and phylogenetic analysis. 16S rRNA gene sequencing was performed as described previously (Morey et al., 2006). DNA for $16 \mathrm{~S}$ rRNA gene sequence determination was extracted and purified with a QIAamp DNA Mini kit (Qiagen) and amplified by using the Expand high-fidelity PCR system (Roche) with primers fD1 and rP2 (Weisburg et al., 1991). Excess deoxynucleoside triphosphates and primers were removed with magnetic carboxylate beads (Agencourt Bioscience). Cycle sequencing was performed with Big Dye version 3.1 dye terminator chemistry (Applied Biosystems) using 16 primers by previously described methods (Morey et al., 2006). Excess dyes were removed with magnetic carboxylate beads (Agencourt Bioscience), and reaction products were sequenced on an ABI 3100 sequencer (Applied Biosystems). The sequence data were edited and compiled using the Wisconsin Sequence Analysis Package (Genetics Computer Group). The novel and reference 16S rRNA gene sequences were aligned with sequences from GenBank using the pairwise alignment algorithm in MacClade version 4.08 (Maddison \& Maddison, 2005). The multiple sequence alignment was edited manually to remove terminal regions that were not represented by all members. PHYML 3.0 (Guindon \& Gascuel, 2003) was used to infer a maximum-likelihood tree and to perform an additional bootstrap analysis (500 replicates). The model of molecular evolution used in the analysis was the HKY +I model as inferred by the corrected Akaike Information Criterion in the jmodelTest package 0.1.1 (Posada, 2008). The 16S rRNA gene sequences of FSL S4-isolates were submitted to GenBank and assigned the accession numbers EU545980 to EU545983. The type strain FSL S4-120 $0^{\mathrm{T}}$ was designated 
ATCC BAA- $1595^{\mathrm{T}}$ corresponding to GenBank accession number EU545982. Additionally, 16S rRNA gene sequences of five species of the genus Listeria were submitted to GenBank (Supplementary Table S1).

Sequencing of sigB, gap and prs and sequence analysis. In addition to phylogenetic analysis of $16 \mathrm{~S}$ rRNA gene sequences, a phylogenetic analysis was performed based on partial sequences of three protein coding genes, including sigB, which encodes an alternative sigma factor involved in stress response, and the housekeeping genes gap and prs, which encode glyceraldehyde-3phosphate dehydrogenase and phosphoribosylpyrophosphate synthase (see Nightingale et al., 2005b for more information). Sequencing of part of these genes was performed as previously described (Nightingale et al., 2005b); new primers were designed to amplify prs in L. ivanovii, L. seeligeri, L. welshimeri, L. innocua and the FSL S4-isolates (HdB40prsF 5'-CCAAATTAACATTGAAGAAAGTATCCGTGGTTGTC-3' and HdB41prsR 5'-GAACTTACAGAWGCATTYTCATGWAC-3'). To further probe the phylogenetic position of the FSL S4-isolates, a phylogenetic analysis was performed with the concatenated sigB-gap-prs sequences. The entire alignment was $1760 \mathrm{bp}$ long (sigB: $653 \mathrm{bp}$, gap: $568 \mathrm{bp}$ and prs: $539 \mathrm{bp}$ ). PHYML 3.0 was used to perform the maximum-likelihood analysis and an additional bootstrap analysis (500 replicates) to infer branch support. The model of molecular evolution used in the analysis was the GTR + G+I model as inferred with the corrected Akaike Information Criterion in the jmodelTest package 0.1.1. The sigB, gap and prs sequences of the FSL S4-isolates were submitted to GenBank (Supplementary Table S3).

Automated ribotyping. All four FSL S4-isolates were characterized by automated ribotyping using the restriction enzyme EcoRI and the RiboPrinter Microbial Characterization System (Qualicon) according to the manufacturer's instructions and as previously described in detail (Gray et al., 2004).

Restriction fragment length polymorphism analysis using pulsed-field gel electrophoresis. The FSL S4-isolates and other species of the genus Listeria were characterized using AscI and ApaI restriction endonucleases in accordance with the PulseNet standardized protocol (Graves \& Swaminathan, 2001). Agarose gel images obtained using Gel Doc 2000 were converted to TIFF image files and analysed using BioNumerics (Applied Maths) software version 4.0, PulseNet customized version (Graves et al., 2005).

Virulence gene PCR assays. All FSL S4-isolates were characterized using PCR assays (Supplementary Table S4) to screen for the presence of the six virulence genes located in the L. monocytogenes prfA virulence gene island (i.e. prfA, plcA, hly, $m p l$, actA and $p l c B$ ) (Nightingale et al., 2005b; Norton et al., 2001; Orsi et al., 2008; Wiedmann et al., 1997) and to screen for the presence of inlA (Nightingale et al., 2005a).

Sequencing of the prs-Idh intergenic region. The L. monocytogenes virulence gene island is located between prs and $l d h$; to probe for presence of virulence genes in this region, the region between prs and $l d h$ was sequenced in FSL S4-696. This region was PCR amplified with the primer pair LMVI-F (which anneals in prs) and LMVI-R (which anneals in $l d h$ ) (Cai \& Wiedmann, 2001) and then sequenced with these primers as well as internal primers, using a primer walking strategy. The final sequence for this region was assembled in Sequencher 4.8 (Gene Codes). Alignments were made in MacClade 4.08 and nucleotide identities of the individual ORFs were calculated using PAUP (Swofford, 2002). The sequence of the ldh-prs intergenic region of FSL S4-696 is deposited under GenBank accession number FJ692340.
Molecular serotyping. Molecular serotyping was performed using a previously described multiplex PCR assay (Doumith et al., 2004a), which detects serotype-specific marker genes. This assay differentiates five L. monocytogenes profiles and classifies the four most common disease-associated serotypes (i.e. $1 / 2 \mathrm{a}, 1 / 2 \mathrm{~b}, 1 / 2 \mathrm{c}$ and $4 \mathrm{~b}$ ) into unique serogroups. Each multiplex PCR profile contains $L$. monocytogenes isolates belonging to more than one serotype, including profile IIa (serotypes $1 / 2 \mathrm{a}$ and $3 \mathrm{a}$ ), IIb (serotypes $1 / 2 \mathrm{~b}$, $3 \mathrm{~b}$ and 7 ), IIc (serotypes $1 / 2 \mathrm{c}$ and $3 \mathrm{c}$ ), IVb (serotypes $4 \mathrm{~b}, 4 \mathrm{~d}$ and $4 \mathrm{e}$ ) and L (serotypes $4 \mathrm{a}$ and $4 \mathrm{c}$ ), as noted previously (Doumith et al., 2005).

Tissue culture invasion assays. Invasiveness for human intestinal epithelial cells of all four FSL S4-isolates was determined using Caco-2 cells (ATCC HTB 37) as previously described (Nightingale et al., 2005a). L. monocytogenes 10403 S (Bishop \& Hinrichs, 1987) and L. innocua FSL C2-008 were used as control strains in these assays. Briefly, bacterial cells were grown overnight $(16-18 \mathrm{~h})$ at $30{ }^{\circ} \mathrm{C}$ to stationary phase, and confluent Caco-2 monolayers grown in a 24 -well plate were inoculated with approximately $2 \times 10^{7}$ c.f.u. of the test isolates ( 3 wells per strain). After incubation for $30 \mathrm{~min}$, Caco- 2 cells were washed three times with PBS, and at 45 min postinoculation, fresh medium containing gentamicin $\left(150 \mu \mathrm{g} \mathrm{ml}^{-1}\right)$ was added to kill extracellular bacteria. At $90 \mathrm{~min}$ post-inoculation, Caco- 2 cells were washed three times with PBS; they were lysed by addition of ice-cold sterile distilled water and vigorous pipetting. Intracellular numbers of the bacteria were determined by plating lysed Caco-2 cell suspensions on BHI agar. Invasion efficiency was calculated as the number of intracellular bacteria recovered (in c.f.u.) relative to the bacterial numbers (in c.f.u.) used for the inoculation.

\section{RESULTS}

\section{Phenotypic characteristics and temperature limits of FSL S4-isolates}

The four FSL S4-isolates were identified by the API Identification System as L. monocytogenes/L. innocua (octal code 6110; rhamnose- and xylose-negative). By conventional biochemical profiles, all four isolates were positive for catalase activity, aesculin hydrolysis, hydrogen sulfide production, and the methyl red test; negative for oxidase activity; tolerant of sodium chloride; positive for assimilation of D-glucose, lactose and maltose; and negative for assimilation of D-xylose, D-mannitol, sucrose and L-rhamnose, nitrate reduction, urease activity, indole production and gelatin hydrolysis. The FSL S4-isolates were short, Gram-positive rods that were motile at $25-30{ }^{\circ} \mathrm{C}$, were non-haemolytic on $5 \%$ sheep blood agar (SBA) and RBA at $37^{\circ} \mathrm{C}$, and did not grow on MacConkey, Salmonella-Shigella, citrate or cetrimide agars. The optimum growth temperature for FSL S4$120^{\mathrm{T}}$ was between 30 and $37^{\circ} \mathrm{C}$. The temperature limits of growth were $1-45^{\circ} \mathrm{C}$ in trypticase soy broth. The organism did not survive heating at $60{ }^{\circ} \mathrm{C}$ for $30 \mathrm{~min}$. Strain FSL S4-120 $0^{\mathrm{T}}$ was streaked onto SBA and brain heart infusion agar plates, then stored at $4{ }^{\circ} \mathrm{C}$ inside a plastic zip lock bag; after 15 days of storage, tiny colonies were visible. The colonies continued to increase in size and were viable for $>30$ days. 


\section{Molecular characterization methods classified the four FSL S4-isolates as either $L$. monocytogenes or $L$. innocua}

Initial molecular characterization using the AccuProbe test identified the four FSL S4-isolates as L. monocytogenes. The four FSL S4-isolates were classified as profile L by the multiplex PCR molecular serogrouping method of Doumith et al. (2005). Profile L is characterized by amplification of the prs control amplicon, but absence of amplification of any of the serogroup specific genes; profile $\mathrm{L}$ has previously been found to be typical for $L$. monocytogenes isolates belonging to lineage III (Doumith et al., 2004b; Wiedmann et al., 1997). Strains in lineage III represent serotypes $4 \mathrm{a}$ and $4 \mathrm{c}$ as well as atypical serotype $4 \mathrm{~b}$ isolates (Nightingale et al., 2007; Roberts et al., 2006). Since isolates representing species of the genus Listeria other than L. monocytogenes can also show profile L (Doumith et al., 2004b), molecular serogrouping was not useful for obtaining species-level identification of the four FSL S4isolates.

Characterization of the four FSL S4-isolates by automated EcoRI ribotyping yielded highly similar EcoRI ribotypes (Supplementary Table S1). Isolates FSL S4-696 and FSL S4710 had the same DNA fragment pattern, characterized by the presence of an additional fragment of approximately $10 \mathrm{~kb}$ that was absent from the other two isolates. The DNA fragment pattern of FSL S4- $120^{\mathrm{T}}$ had a unique DNA fragment of approximately $30-40 \mathrm{~kb}$. None of the EcoRI ribotype patterns for these four isolates allowed for specific identification by the RiboPrinter database (ribotype patterns are identified to the species level if the test pattern matches a pattern in the DuPont database with a similarity score of $>0.85 \%$ ). The closest EcoRI ribotype matches for all four isolates were L. monocytogenes ribotype patterns in the DuPont database, but the similarity scores for these matches were only between $0.69 \%$ and $0.75 \%$.

The four FSL S4-isolates had unique PFGE patterns when their DNA was restricted with AscI or ApaI restriction endonucleases. Although the individual PFGE patterns of the four isolates were different, a composite dendrogram generated using AscI and ApaI restriction endonucleases clustered all four of the isolates together when compared with a well-characterized L. monocytogenes strains set (Fugett et al., 2006) and a representation of other species of the genus Listeria (Supplementary Fig. S2).

\section{Phylogenetic analysis of 165 rRNA gene and sigB- gap-prs sequence data consistently clustered FSL S4-isolates separately from $L$. monocytogenes and $L$. innocua}

Initial 16S rRNA gene sequence analysis (Fig. 1) showed that all four isolates representing FSL S4-isolates grouped together with a high bootstrap support $(95 \%)$ and formed a clade separate from $L$. monocytogenes and $L$. innocua. The close phylogenetic relationship of the FSL S4-isolates with L. monocytogenes and L. innocua was demonstrated by the fact that they were found in a wellsupported ( $76 \%$ bootstrap support) clade together with these species. The phylogenetic relationships between the FSL S4-isolates, $L$. innocua and $L$. monocytogenes remained without significant bootstrap support and therefore remain unresolved by the $16 \mathrm{~S}$ sequence analysis (Fig. 1). This may be explained by the high similarity between sequences of the FSL S4-isolates and $L$. monocytogenes (99.8-99.3\%) and L. innocua (99\%) and the low number of phylogenetically informative sites in the 16S rRNA gene fragment analysed. To further characterize the phylogenetic position of the FSL S4isolates, partial sigB, gap and prs sequences were obtained for the four FSL S4-isolates and used together with partial sigB, gap and prs sequences for selected $L$. monocytogenes and other Listeria isolates to construct a maximum-likelihood (ML) tree. The concatenated $\operatorname{sig} B$, gap and prs sequences proved to be more phylogenetically informative (148 parsimony informative characters within the L. innocua, L. monocytogenes and FSL S4isolates clade, versus only 6 parsimony informative characters for the 16S rRNA gene). The ML tree based on the concatenated partial sigB, gap and prs sequences showed that the four FSL S4-isolates clustered together (bootstrap support of $99 \%$ ) forming a sistergroup of $L$. monocytogenes (Fig. 2).

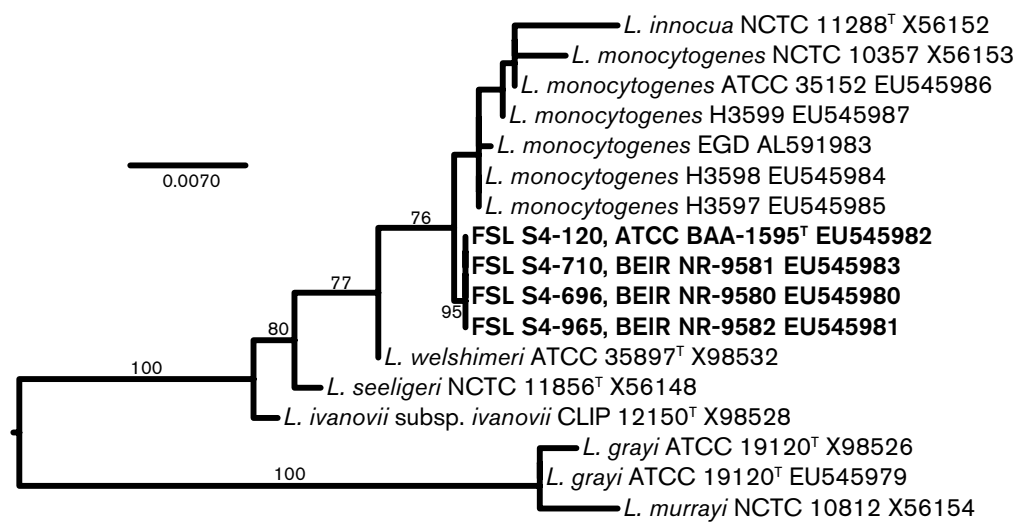

http://ijs.sgmjournals.org
Fig. 1. Maximum-likelihood phylogram based on 16S rRNA gene sequences (1398 nucleotide positions) showing the phylogenetic position of FSL S4-isolates and other species of the genus Listeria. Bootstrap analysis was done with 500 replicates; bootstrap values are indicated above the clades and bootstrap values $<60 \%$ are not shown. Bar, number of inferred substitutions per nucleotide site. GenBank accession numbers for sequences are shown. 


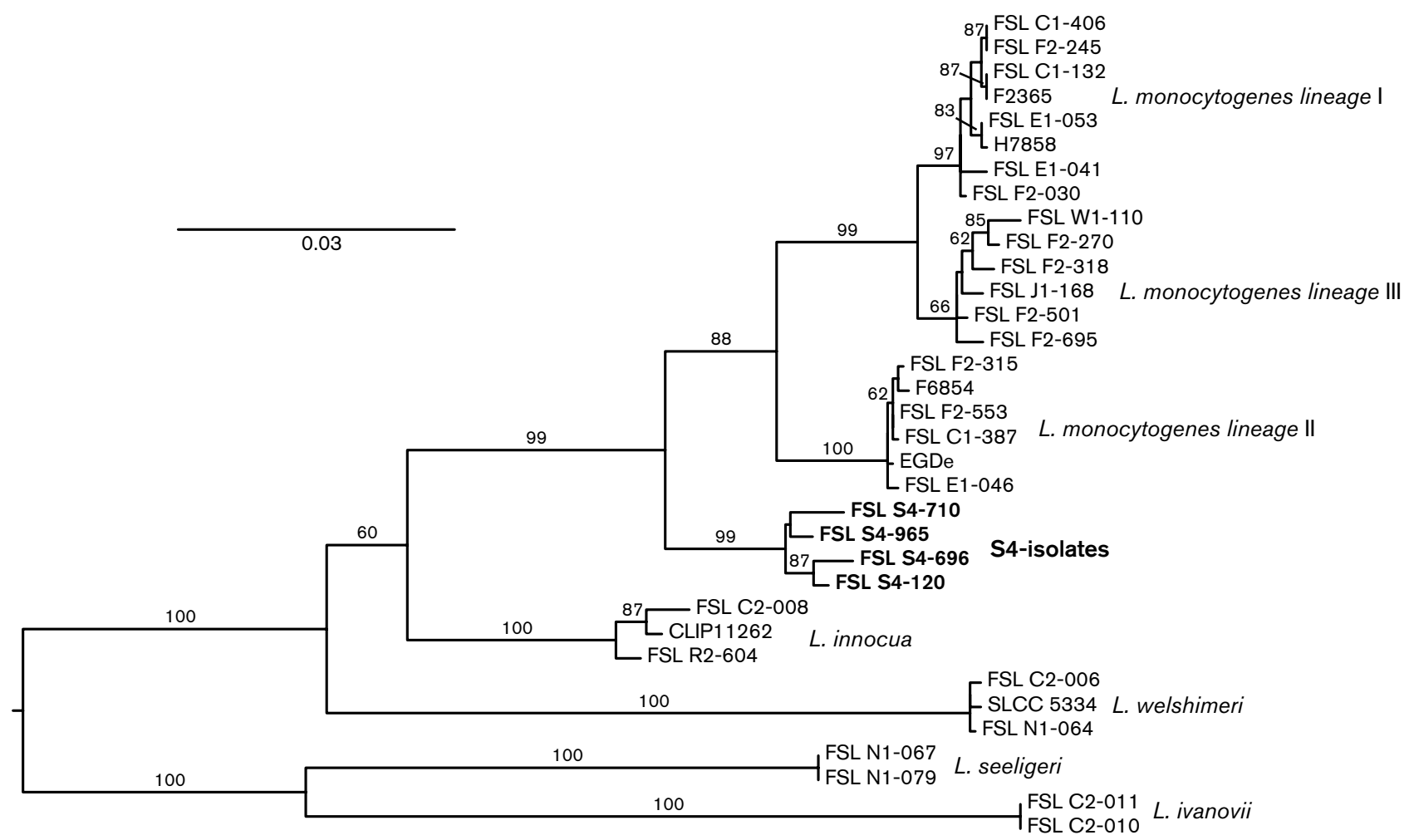

Fig. 2. Phylogram based on maximum-likelihood analysis of concatenated sigB, gap and prs sequences (1760 nucleotide positions total) from the four FSL S4-isolates as well as selected isolates representing other species of the genus Listeria. Values above the clades represent bootstrap values based on 500 replicates (values $<60 \%$ are not shown). Sequence data for L. monocytogenes isolates were obtained from Cai et al. (2002), Roberts et al. (2006) and Nightingale et al. (2005b); sequence data for L. innocua, L. seeligeri, L. welshimeri and L. ivanovii can be found in GenBank (accession numbers are shown in Supplementary Table S3). Bar, number of inferred substitutions per nucleotide site.

\section{FSL S4-isolates lacked the prfA virulence genes cluster and inIA and were non-invasive in Caco-2 cells}

PCR-based screens found no evidence of the presence of the six $L$. monocytogenes virulence genes in the prfA virulence gene island (i.e. prfA, plcA, hly, $m p l$, act $A$ and $p l c B$ ) or for the presence of $i n l A$ in the four FSL S4-isolates. The absence of the prfA virulence gene island was further confirmed by sequencing the ldh-prs intergenic region. The intergenic region contained four open reading frames (Fig. 3 ), three of which are homologues to ORFA, ORFB and ORFZ that have been previously reported in L. innocua and L. monocytogenes (Cai \& Wiedmann, 2001). The fourth ORF (designated $\mathrm{ORFZ}^{\star}$ ) had a high sequence similarity to the FSL S4-isolate ORFZ (74\% nucleotide identity). FSL S4-isolates thus contained a duplicated ORFZ, with ORFZ* representing an ancient orthologue of ORFZ (Fig. 3), as ORFZ $^{*}$ shared only $74 \%$ and $73 \%$ nucleotide identity with the ORFZ of L. monocytogenes and L. innocua, respectively, while FSL S4 ORFZ shared a higher homology with $L$. monocytogenes and L. innocua ORFZ (80\% and $78 \%$, respectively).

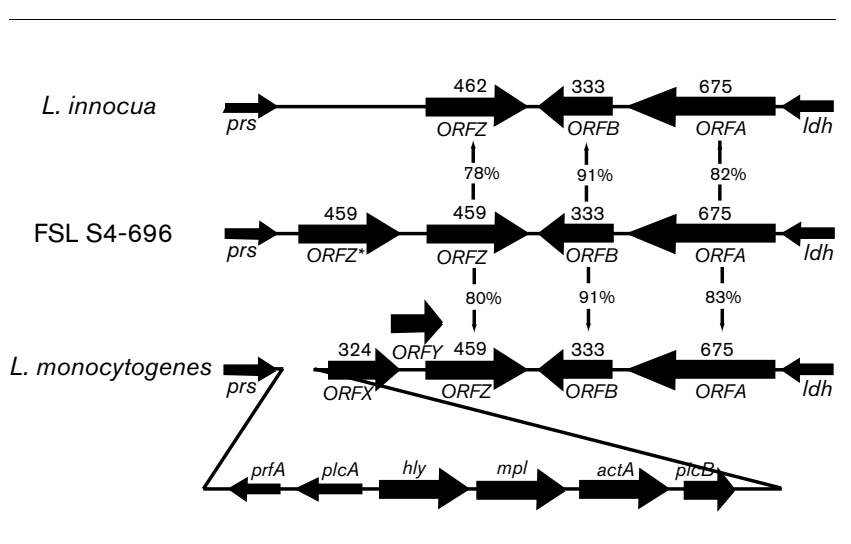

Fig. 3. Schematic overview and comparison of the genetic organization of the ldh-prs intergenic region in FSL S4-696, L. innocua and L. monocytogenes. Names and lengths in bp of the different ORFs are indicated. ORFZ* represents an orthologue of ORFZ. Arrows between the ORFs in the different species indicate the percentage homology. 
In addition, tissue culture invasion assays using the human intestinal epithelial cell line Caco-2 showed that all four FSL S4-isolates had extremely low levels of invasiveness (0.001-0.002\%), which was similar to the L. innocua control strain FSL C2-008 (invasion efficiency of $0.003 \%$ ) and $>100$-fold lower than the invasion efficiency for an $L$. monocytogenes control strain $(1.44 \%)$. These data provide phenotypic support for the absence of the main $L$. monocytogenes virulence genes in these isolates.

\section{The FSL S4-isolates shared a common cellular fatty acid (CFA) profile}

The FSL S4-isolates shared a common CFA profile, characterized by major amounts of branched chain acids, including iso- $\mathrm{C}_{15: 0}(3-15 \%)$, anteiso- $\mathrm{C}_{15: 0}(41-57 \%)$, iso- $\mathrm{C}_{16: 0}(1-7 \%)$, iso- $\mathrm{C}_{17: 0}(1-4 \%)$ and anteiso- $\mathrm{C}_{17: 0}$ (13-36\%). They also contained $\mathrm{C}_{16: 0}(4-7 \%), \mathrm{C}_{18: 1} \omega 9 \mathrm{c}$ $(1-3 \%)$ and $\mathrm{C}_{18: 0}(1-3 \%)$. This profile is essentially identical to other species of the genus Listeria tested and, therefore, FSL S4-isolates cannot be differentiated from other species of this genus by CFA analysis.

\section{DNA/DNA hybridization data indicate that FSL S4-isolates represent a new species separate from $L$. monocytogenes and $L$. innocua}

Results from the DNA relatedness studies are shown in Table 1. DNA from FSL S4-120 $0^{\mathrm{T}}$ was labelled with $\left[{ }^{32} \mathrm{P}\right] \mathrm{dCTP}$ and tested for relatedness to the three other FSL S4 strains, two L. monocytogenes strains (ATCC $15313^{\mathrm{T}}$ and ATCC 35152), one L. innocua strain (ATCC 33090 ${ }^{\mathrm{T}}$ ), and one atypical strain of L. monocytogenes (H3597). Labelled DNA from the type strain showed an average of $82 \%$ relatedness to the three other FSL S4 strains (range, $71-90 \%)$ in reactions at $55{ }^{\circ} \mathrm{C}$. The divergence in related
DNA sequences was between $0.0 \%$ and $0.5 \%$. In reactions at $70{ }^{\circ} \mathrm{C}$, labelled FSL S4 DNA showed an average of $76 \%$ relatedness (range, 71-80\%). Labelled DNA from FSL S4$120^{\mathrm{T}}$ showed an average of $73 \%$ relatedness to the two $L$. monocytogenes strains, L. innocua and strain H3597 (range, $69-75 \%$ ) in reactions at $55{ }^{\circ} \mathrm{C}$, but the divergence in related DNA sequences was between $7.5 \%$ and $9.5 \%$. In reactions at $70{ }^{\circ} \mathrm{C}$, the labelled FSL S4- $120^{\mathrm{T}}$ strain DNA showed an average of $45 \%$ relatedness to the two $L$. monocytogenes strains, L. innocua and strain H3597 (range, 30-53\%). Labelled DNA from L. monocytogenes type strain ATCC $15313^{\mathrm{T}}$ showed an average of $64 \%$ relatedness to the four FSL S4 strains (range, 60-67\%) in reactions at $55{ }^{\circ} \mathrm{C}$. The divergence in related DNA sequences was between $7.0 \%$ and $8.0 \%$. In reactions at $70{ }^{\circ} \mathrm{C}$, labelled $L$. monocytogenes DNA, exhibited an average of $35 \%$ relatedness to the four FSL S4 strains.

\section{DISCUSSION}

We have characterized isolates from the natural environment that, by colony morphology, resembled $L$. innocua and other non-haemolytic species of the genus Listeria, but that represent a novel species that may be initially differentiated from other species of this genus based on a positive result with the AccuProbe test and the absence of the distinct haemolysis produced on blood agar by species other than L. welshimeri, L. grayi and L. innocua. Consequently, for definitive identification, a polyphasic approach is required. Molecular subtyping methods clustered the four isolates representing this novel species together when compared with $L$. monocytogenes and other species of the genus Listeria. Furthermore, phylogenetic analysis of 16S, sigB, gap and prs sequence data consistently clustered the FSL S4-isolates separately from L. monocytogenes and $L$. innocua. The phylogenetic position with

Table 1. DNA relatedness of FSL S4-isolates and Listeria monocytogenes, Listeria innocua and an atypical Listeria monocytogenes strain

RBR, Relative binding ratio; \% $\mathrm{D}$, percentage divergence.

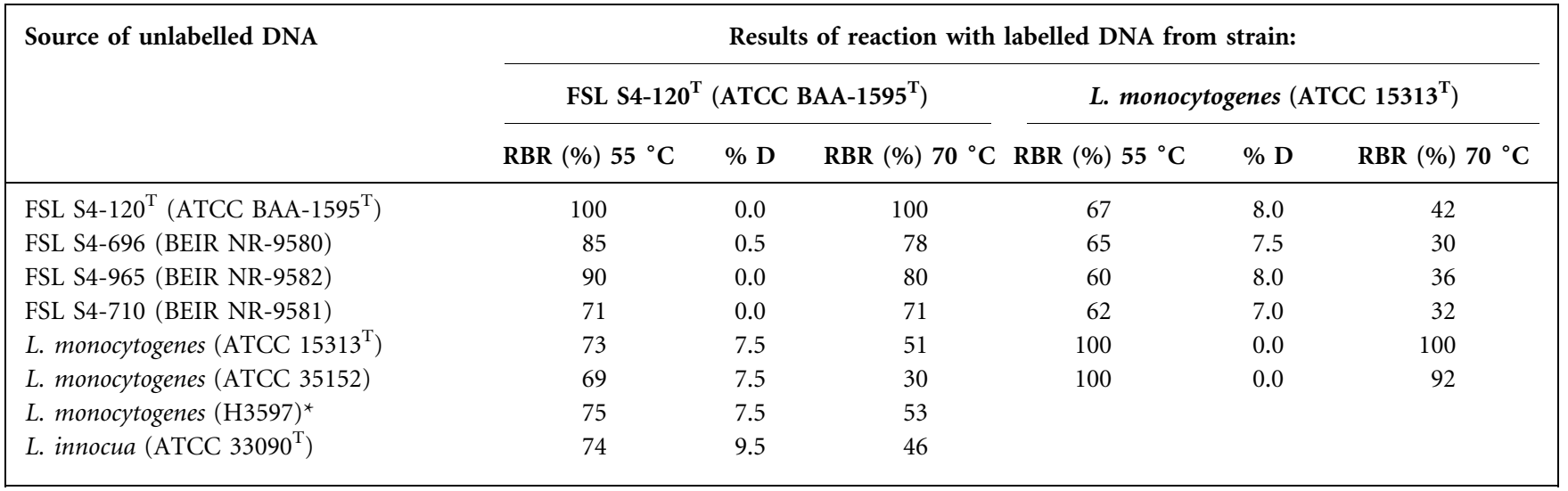

*Atypical Listeria monocytogenes; L-rhamnose-negative. 
respect to L. innocua and L. monocytogenes of the FSL S4isolates, however, could not be unambiguously resolved by $16 \mathrm{~S}$ rRNA gene phylogenetic analysis, mainly because of the lack of phylogenetically informative sites in the $16 \mathrm{~S}$ rRNA gene of members of the genus Listeria (Collins et al., 1991; Czajka et al., 1993). The sigB, gap and prs sequence data proved to be more phylogenetically informative. Analysis of the sigB, gap and prs sequence data placed the FSL S4-isolates in a well-supported sistergroup to $L$. monocytogenes. In addition, the PCR-based screens and sequencing of the prs-ldh intergenic region found no evidence for the presence of the six L. monocytogenes virulence genes in the prfA virulence gene island or for the presence of inlA in the four FSL S4-isolates. Tissue culture invasion assay data phenotypically confirm the absence of the main $L$. monocytogenes virulence genes in these isolates.

Johnson et al. (2004) investigated a novel haemolytic strain of Listeria that was unusually difficult to identify to the species level by the conventional methods. The issue was resolved by using total DNA-DNA hybridization testing and confirmed by specific PCR-based tests including a Listeria microarray assay. Their study documented the first naturally occurring haemolytic strains of L. innocua. Our DNA relatedness data indicate that the FSL S4-isolates constitute a new species of the genus Listeria. According to established molecular criteria for species-level relatedness, DNA data of strains that are $70 \%$ or more related at optimal conditions and DNA-related sequences that show $5 \%$ or less divergence are sufficient to identify bacteria to the species level, even in the absence of phenotypic data (Brenner et al., 1982; Wayne et al., 1987). In the DNADNA hybridization analysis reported here, FSL S4-120 exhibited $73 \%, 69 \%, 75 \%$ and $74 \%$ similarity under low stringency conditions and $51 \%, 30 \%, 53 \%$ and $46 \%$ similarity under high stringency conditions to L. monocytogenes (ATCC $15313^{\mathrm{T}}$ ), L. monocytogenes (ATCC 35152), L. monocytogenes (H3597) and L. innocua $\left(\mathrm{ATCC} 33090^{\mathrm{T}}\right.$ ), respectively. The values for hybridization reactions at optimal conditions were close to the recommended threshold value and the values at less-than-optimal condition were below the threshold value for defining a new species. However, the divergence in related nucleotide sequences was $7.5 \%$ for $L$. monocytogenes and $9.5 \%$ for $L$. innocua strains tested, well above the recommended $5 \%$ threshold value for divergence in related nucleotide sequences (Brenner et al., 1982; Stackebrandt \& Goebel, 1994; Wayne et al., 1987), hence supporting the distinct position of FSL S4-isolates within the genus Listeria. Conversely, labelled DNA from L. monocytogenes (ATCC $15313^{\mathrm{T}}$ ) and DNA from the four FSL S4-isolates had average similarities of $63.5 \%$ under optimal and $35.0 \%$ under less-than-optimal conditions, respectively, while the average divergence within related sequences was greater than $7.6 \%$. This novel species not only represents an important branching point in Listeria phylogeny that can help further our understanding of this group of closely related pathogenic and non-pathogenic species, but also may present a diagnostic challenge for clinical, food and public health microbiologists who are seeking to identify $L$. monocytogenes, the human pathogen. On the basis of the phenotypic and genotypic properties presented, the FSL S4-isolates should be assigned to a novel species of the genus Listeria, for which the name Listeria marthii sp. nov. is proposed.

\section{Description of Listeria marthii sp. nov.}

Listeria marthii (mar'thi.i. N.L. gen. masc. n. marthii after Emeritus Professor Elmer H. Marth, for his research and contributions on Listeria monocytogenes).

L. marthii exhibits characteristics of the genus Listeria as reported by Rocourt \& Buchrieser (2007). Cells are small, regular, Gram-positive rods with rounded ends. Grows well on most commonly used bacteriological media. The temperature range for growth is $1-45{ }^{\circ} \mathrm{C}$ (optimal growth at $30-37^{\circ} \mathrm{C}$ ). Motile, non-sporing, aerobic and facultatively anaerobic. Form an umbrella-type growth appearing 3-5 $\mathrm{mm}$ below the surface of a stabbed semisolid motility medium incubated at $20-30{ }^{\circ} \mathrm{C}$, but not at $37^{\circ} \mathrm{C}$. Colonies are non-haemolytic on agar surface and in stab on SBA and RBA after incubating for $18-24 \mathrm{~h}$ at $37{ }^{\circ} \mathrm{C}$. On clear, solid media colonies are $0.2-0.8 \mathrm{~mm}$ in diameter, smooth, bluish grey, translucent and slightly raised with a fine surface texture and entire margin after incubating for $24 \mathrm{~h}$ at $37^{\circ} \mathrm{C}$. Colonies present a characteristic blue-green iridescence typical of Listeria on clear medium when viewed by oblique light. Positive for catalase activity, aesculin hydrolysis, hydrogen sulfide production and the methyl red test; negative for oxidase activity; tolerant of sodium chloride; positive for assimilation of D-glucose, lactose and maltose; and negative for assimilation of Dxylose, D-mannitol, sucrose and L-rhamnose, nitrate reduction, urease activity, indole production and gelatin hydrolysis.

The type strain is FSL S4- $120^{\mathrm{T}}\left(=\mathrm{J} 3452^{\mathrm{T}}=\mathrm{H} 3507^{\mathrm{T}}\right.$ $=$ ATCC BAA $-1595^{\mathrm{T}}=$ BEIR NR $9579^{\mathrm{T}}=$ CCUG $56148^{\mathrm{T}}$ ) isolated from environmental samples collected in the Finger Lakes National Forest, New York, USA. Three additional L. marthii isolates are registered in the Biodefence and Emerging Infections Research Resources Repository (BEIR), Manassas, VA and the CCUG.

\section{ACKNOWLEDGEMENTS}

We thank Dr Tim Liburn, Dianet Giraldo and Dr Enevold Falsen for their generous assistance with depositing the cultures in collections and Dr Hans Trüper for his kind advice regarding correct Latin etymology. We also thank Dr Don Brenner for his helpful discussions, Dr Peter Gerner-Smidt for critical reading of the manuscript, and Steven Strokia for kindly generating the PFGE dendrogram. This project was partially supported by US Department of Agriculture Special Research Grant \#2005-34459-15625 (to M. W.). Use of trade names is for identification only and does not imply endorsement by the Public Health Service or by the US Department of Health and Human Services. The findings and conclusions in this report are those 
of the author(s) and do not necessarily represent the official position of the Centers for Disease Control and Prevention.

\section{REFERENCES}

Bille, J., Catimel, B., Bannerman, E., Jacquet, C., Yersin, M. N., Caniaux, I., Monget, D. \& Rocourt, J. (1992). API Listeria, a new and promising one-day system to identify Listeria isolates. Appl Environ Microbiol 58, 1857-1860.

Bishop, D. K. \& Hinrichs, D. J. (1987). Adoptive transfer of immunity to Listeria monocytogenes. The influence of in vitro stimulation on lymphocyte subset requirements. J Immunol 139, 2005-2009.

Boerlin, P., Rocourt, J., Grimont, F., Grimont, P. A. D., Jacquet, C. C. \& Piffaretti, J.-C. (1992). Listeria Ivanovii subsp. londoniensis subsp. nov. Int J Syst Bacteriol 42, 69-73.

Bonner, T. I., Brenner, D. J., Neufeld, B. R. \& Britten, R. J. (1973). Reduction in the rate of DNA reassociation by sequence divergence. J Mol Biol 81, 123-135.

Brenner, D. J., McWhorter, A. C., Knutson, J. K. L. \& Steigerwalt, A. G. (1982). Escherichia vulneris: a new species of enterobacteriaceae associated with human wounds. J Clin Microbiol 15, 1133-1140.

Cai, S. \& Wiedmann, M. (2001). Characterization of the prfA virulence gene cluster insertion site in non-hemolytic Listeria spp.: probing the evolution of the Listeria virulence gene island. Curr Microbiol 43, 271-277.

Cai, S., Kabuki, D. Y., Kuaye, A. Y., Cargioli, T. G., Chung, M. S., Nielsen, R. \& Wiedmann, M. (2002). Rational design of DNA sequence-based strategies for subtyping Listeria monocytogenes. J Clin Microbiol 40, 3319-3325.

Collins, M. D., Wallbanks, S., Lane, D. J., Shah, J., Nietupski, R., Smida, J., Dorsch, M. \& Stackebrandt, E. (1991). Phylogenetic analysis of the genus Listeria based on reverse transcriptase sequencing of 16S rRNA. Int J Syst Bacteriol 41, 240-246.

Czajka, J., Bsat, N., Piani, M., Russ, W., Sultana, K., Wiedmann, M., Whitaker, R. \& Batt, C. A. (1993). Differentiation of Listeria monocytogenes and Listeria innocua by $16 \mathrm{~S}$ rRNA genes and intraspecies discrimination of Listeria monocytogenes strains by random amplified polymorphic DNA polymorphisms. Appl Environ Microbiol 59, 304-308.

Doumith, M., Buchrieser, C., Glaser, P., Jacquet, C. \& Martin, P. (2004a). Differentiation of the major Listeria monocytogenes serovars by multiplex PCR. J Clin Microbiol 42, 3819-3822.

Doumith, M., Cazalet, C., Simoes, N., Frangeul, L., Jacquet, C., Kunst, F., Martin, P., Cossart, P., Glaser, P. \& Buchrieser, C. (2004b). New aspects regarding evolution and virulence of Listeria monocytogenes revealed by comparative genomics and DNA arrays. Infect Immun 72, 1072-1083.

Doumith, M., Jacquet, C., Gerner-Smidt, P., Graves, L. M., Loncarevic, S., Mathisen, T., Morvan, A., Salcedo, C., Torpdahl, M. $\&$ other authors (2005). Multicenter validation of a multiplex PCR assay for differentiating the major Listeria monocytogenes serovars 1/2a, 1/2b, 1/2c, and 4b: toward an international standard. J Food Prot 68, 2648-2650.

Fugett, E., Fortes, E., Nnoka, C. \& Wiedmann, M. (2006). International Life Sciences Institute North America Listeria monocytogenes strain collection: development of standard Listeria monocytogenes strain sets for research and validation studies. J Food Prot 69, 2929-2938.

Gouin, E., Mengaud, J. \& Cossart, P. (1994). The virulence gene cluster of Listeria monocytogenes is also present in Listeria ivanovii, an animal pathogen, and Listeria seeligeri, a nonpathogenic species. Infect Immun 62, 3550-3553.
Graves, L. M. \& Swaminathan, B. (2001). PulseNet standardized protocol for subtyping Listeria monocytogenes by macrorestriction and pulsed-field gel electrophoresis. Int J Food Microbiol 65, 55-62.

Graves, L. M., Hunter, S. B., Ong, A. R., Schoonmaker-Bopp, D., Hise, K., Kornstein, L., DeWitt, W. E., Hayes, P. S., Dunne, E. \& other authors (2005). Microbiological aspects of the investigation that traced the 1998 outbreak of Listeriosis in the United States to contaminated hot dogs and establishment of molecular subtypingbased surveillance for Listeria monocytogenes in the PulseNet Network. J Clin Microbiol 43, 2350-2355.

Gray, M. J., Zadoks, R. N., Fortes, E. D., Dogan, B., Cai, S., Chen, Y., Scott, V. N., Gombas, D. E., Boor, K. J. \& Wiedmann, M. (2004). Listeria monocytogenes isolates from foods and humans form distinct but overlapping populations. Appl Environ Microbiol 70, 5833-5841.

Guindon, S. P. \& Gascuel, O. (2003). A simple, fast, and accurate algorithm to estimate large phylogenies by maximum likelihood. Syst Biol 52, 696-704.

Hain, T., Chatterjee, S. S., Ghai, R., Kuenne, C. T., Billion, A., Steinweg, C., Domann, E., Kärst, U., Jänsch, L. \& other authors (2007). Pathogenomics of Listeria spp. Int J Med Microbiol 297, 541557.

Johnson, J., Jinneman, K., Stelma, G., Smith, B. G., Lye, D., Messer, J., Ulaszek, J., Evsen, L., Gendel, S. \& other authors (2004). Natural atypical Listeria innocua strains with Listeria monocytogenes pathogenicity island 1 genes. Appl Environ Microbiol 70, 4256-4266.

Kuhn, M. \& Goebel, W. (2007). Molecular virulence determinants of Listeria monocytogenes. In Listeria, Listeriosis, and Food Safety, 3rd edn, pp. 111-155. Edited by E. T. Ryser and E. H. Marth. Boca Raton, FL: CRC Press.

Maddison, D. R. \& Maddison, W. P. (2005). MacClade. Sunderland, MA: Sinauer Associates.

Mandel, M., Igambi, L., Bergendahl, J., Dodson, M. L., Jr \& Scheltgen, E. (1970). Correlation of melting temperature and cesium chloride buoyant density of bacterial deoxyribonucleic acid. J Bacteriol 101, 333338.

Morey, R. E., Galloway, R. L., Bragg, S. L., Steigerwalt, A. G., Mayer, L. W. \& Levett, P. N. (2006). Species-specific identification of Leptospiraceae by 16S rRNA gene sequencing. J Clin Microbiol 44, 3510-3516.

Nightingale, K. K., Windham, K., Martin, K. E., Yeung, M. \& Wiedmann, M. (2005a). Select Listeria monocytogenes subtypes commonly found in foods carry distinct nonsense mutations in inlA, leading to expression of truncated and secreted internalin $\mathrm{A}$, and are associated with a reduced invasion phenotype for human intestinal epithelial cells. Appl Environ Microbiol 71, 8764-8772.

Nightingale, K. K., Windham, K. \& Wiedmann, M. (2005b). Evolution and molecular phylogeny of Listeria monocytogenes isolated from human and animal listeriosis cases and foods. J Bacteriol 187, 55375551.

Nightingale, K. K., Lyles, K., Ayodele, M., Jalan, P., Nielsen, R. \& Wiedmann, M. (2006). Novel method to identify source-associated phylogenetic clustering shows that Listeria monocytogenes includes niche-adapted clonal groups with distinct ecological preferences. J Clin Microbiol 44, 3742-3751.

Nightingale, K., Bovell, L., Grajczyk, A. \& Wiedmann, M. (2007). Combined sigB allelic typing and multiplex PCR provide improved discriminatory power and reliability for Listeria monocytogenes molecular serotyping. J Microbiol Methods 68, 52-59.

Ninet, B., Bannerman, E. \& Bille, J. (1992). Assessment of the AccuProbe Listeria monocytogenes culture identification reagent kit for rapid colony confirmation and its application in various enrichment broths. Appl Environ Microbiol 58, 4055-4059. 
Norton, D. M., McCamey, M. A., Gall, K. L., Scarlett, J. M., Boor, K. J. \& Wiedmann, M. (2001). Molecular studies on the ecology of Listeria monocytogenes in the smoked fish processing industry. Appl Environ Microbiol 67, 198-205.

Okwumabua, O., Swaminathan, B., Edmonds, P., Wenger, J., Hogan, J. \& Alden, M. (1992). Evaluation of a chemiluminescent DNA probe assay for the rapid confirmation of Listeria monocytogenes. Res Microbiol 143, 183-189.

Orsi, R. H., Maron, S. B., Nightingale, K. K., Jerome, M., Tabor, H. \& Wiedmann, M. (2008). Lineage specific recombination and positive selection in coding and intragenic regions contributed to evolution of the main Listeria monocytogenes virulence gene cluster. Infect Genet Evol 8, 566-576.

Posada, D. (2008). jModelTest: phylogenetic model averaging. Mol Biol Evol 25, 1253-1256.

Roberts, A., Nightingale, K., Jeffers, G., Fortes, E., Kongo, J. M. \& Wiedmann, M. (2006). Genetic and phenotypic characterization of Listeria monocytogenes lineage III. Microbiology 152, 685-693.

Rocourt, J. \& Buchrieser, C. (2007). The genus Listeria and Listeria monocytogenes: phylogenetic position, taxonomy, and identification. In Listeria, Listeriosis, and Food Safety, 3rd edn, pp. 1-20. Edited by E. T. Ryser and E. H. Marth. Boca Raton, FL: CRC Press.

Rocourt, J., Alonso, J.-M. \& Seeliger, H. P. R. (1983). Virulence comparée des cinq groupes génomiques de Listeria monocytogenes (sensu lato). Ann Inst Pasteur Microbiol 134, 359-364.

Rocourt, J., Hof, H., Schrettenbrunner, A., Malinverni, R. \& Bille, J. (1986). Acute purulent Listeria seelingeri meningitis in an immunocompetent adult. Schweiz Med Wochenschr 116, 248-251.
Sallen, B., Rajoharison, A., Desvarenne, S., Quinn, F. \& Mabilat, C. (1996). Comparative analysis of $16 \mathrm{~S}$ and $23 \mathrm{~S}$ rRNA sequences of Listeria species. Int J Syst Bacteriol 46, 669-674.

Seeliger, H. P. R., Rocourt, J., Schrettenbrunner, A., Grimont, P. A. D. \& Jones, D. (1984). Listeria ivanovii sp. nov. Int J Syst Bacteriol 34, 336-337.

Stackebrandt, E. \& Goebel, B. M. (1994). Taxonomic note: a place for DNA-DNA reassociation and 16S rRNA sequence analysis in the present species definition in bacteriology. Int J Syst Bacteriol 44, 846849.

Swofford, D. L. (2002). PAUP*: Phylogenetic analysis using parsimony (and other methods), version 4. Sunderland, MA: Sinauer Associates.

Wayne, L. G., Brenner, D. J., Colwell, R. R., Grimont, P. A. D., Kandler, O., Krichevsky, M. I., Moore, L. H., Moore, W. E. C., Murray, R. G. E. \& other authors (1987). International Committee on Systematic Bacteriology. Report of the ad hoc committee on reconciliation of approaches to bacterial systematics. Int J Syst Bacteriol 37, 463-464.

Weisburg, W. G., Barns, S. M., Pelletier, D. A. \& Lane, D. J. (1991). $16 \mathrm{~S}$ ribosomal DNA amplification for phylogenetic study. J Bacteriol 173, 697-703.

Weyant, R. S., Moss, C. W., Weaver, R. E., Hollis, D. G., Jordan, J. G., Cook, E. C. \& Daneshvar, M. I. (1996). Identification of Unusual Pathogenic Gram-negative Aerobic and Facultatively Anaerobic Bacteria, 2nd edn. Baltimore: Williams \& Wilkins.

Wiedmann, M., Bruce, J. L., Keating, C., Johnson, A. E., McDonough, P. L. \& Batt, C. A. (1997). Ribotypes and virulence gene polymorphisms suggest three distinct Listeria monocytogenes lineages with differences in pathogenic potential. Infect Immun 65, 2707-2716. 